\title{
Efeito de herbicidas no crescimento inicial do sorgo sacarino
}

\author{
Lucas Tadeu FURQUIM ${ }^{1}$, Patrícia Andrea MONQUERO ${ }^{*}$, Rafael Pires da SILVA ${ }^{1}$ \\ ${ }^{1}$ Departamento de Recursos Naturas e Proteção Ambiental, Universidade Federal de São Carlos, São Carlos, SP, Brasil. \\ *E-mail: pamonque@hotmail.com
}

Recebido em abri1/2018; Aceito em setembro/2018.

RESUMO: A presença de plantas daninhas pode reduzir severamente o rendimento do sorgo sacarino (Sorghum bicolor), e em função do reduzido número de herbicidas registrados, o objetivo do trabalho foi avaliar o efeito de herbicidas no crescimento inicial dessa cultura. O delineamento experimental foi inteiramente casualizado com cinco repetições, sendo o haloxyfop-methyl, cyhalofop-butil, fomesafem, imazaquim, lactofen, atrazine, 2,4-D e saflufenacil aplicados em diferentes doses em pós-emergência inicial da cultura e os herbicidas atrazine, atrazine+simazine, hexazinone e s-metolachlor em pré-emergência da cultura. As avaliações de fitointoxicação foram realizadas aos 7, 14, 21 e 30 dias após a aplicação (DAT) e a biomassa seca da parte aérea avaliada aos 30 DAT. Em pós-emergência, os herbicidas haloxyfop-methyl e imazaquim provocaram alta fitointoxicação e impactos na biomassa das plantas. 2,4-D e atrazine não provocaram diferenças significativas com relação à testemunha tanto em fitointoxicação como na biomassa. O herbicida lactofen provocou baixa fitointoxicação, todavia, saflufenacil e fomesafen promoveram fitointoxicação na dose comercial próximo a $40 \%$ e alterações na biomassa. Dos herbicidas utilizados em pré-emergência, apenas hexazinone e s-metolachlor demonstraram fitointoxicação e alterações na biomassa. Conclui-se que os herbicidas atrazine, lactofen e 2,4-D podem ser utilizados em aplicações em pós-emergência, e atrazine e atrazine+simazine em pré-emergência.

Palavras-chave: fitointoxicação, Sorghum bicolor, pré-emergente, pós-emergente.

\section{Effect of herbicides on the initial growth of sweet sorghum}

\begin{abstract}
The presence of weeds may severely reduce yield of sweet sorghum (Sorghum bicolor), and due to the reduced number of herbicides registered, the objective of this work was to evaluate the effect of herbicides on the initial growth of this crop. The experimental design was completely randomized with five replicate, being, the herbicides haloxyfop-methyl, cyhalofop-butyl, fomesafem, imazaquim, lactofen, atrazine, 2,4-D and saflufenacil were applied at different initial post-emergence rates and herbicides atrazine, atrazine + simazine, hexazinone and s- metolachlor in pre-emergence of the culture. The phytointoxication evaluations were performed at 7, 14, 21 and 30 days after application (DAT) and the dry biomass of the aerial part evaluated at 30 DAT. In post-emergence, the herbicides haloxyfop-methyl and imazaquim caused high phytointoxication and impacts on plant biomass. 2,4-D and atrazine did not cause significant differences in relation to the control in both phytointoxication and biomass. The herbicide lactofen caused low phytointoxication, however, saflufenacil and fomesafen promoted phytointoxication at commercial dose close to $40 \%$ and changes in biomass. Of the herbicides used in pre-emergence, only hexazinone and s-metolachlor demonstrated phytointoxication and changes in biomass. It is concluded that the herbicides atrazine, lactofen and 2,4-D can be used in post-emergence applications, and pre-emergence atrazine and atrazine + simazine.
\end{abstract}

Keywords: phytointoxication, Sorghum bicolor, pre-emergent, post-emergent.

\section{INTRODUÇÃO}

O Sorghum bicolor é uma gramínea originária do continente africano pertencente à família Poaceae, sendo cultivada em inúmeras regiões do planeta. Recentemente a cultura vem sendo considerada como opção para obtenção de bioenergia conduzida na entre safra da cana-de-açúcar por apresentar ciclo curto e produção de matéria verde com alta concentração de açúcares (GIACOMINI et al., 2013).

A qualidade e produtividade de biomassa e a estabilidade de produção de matéria seca ao longo do cultivo estão diretamente ligados à interferência das plantas daninhas, as quais competem com a cultura, por água, luz e nutrientes. A competição com plantas daninhas pode reduzir severamente o rendimento de sorgo, principalmente, quando não são controladas de forma eficaz nas primeiras sete semanas de desenvolvimento da cultura (RODRIGUES et al., 2010; ROSALES-ROBLES et al., 2014). De acordo com Tamado et al. (2002) a convivência das plantas daninhas com o sorgo granífero durante as quatro primeiras semanas após a emergência pode promover redução de 40 a $97 \%$ no rendimento de grãos.

O controle de plantas daninhas pode ser feito de inúmeras maneiras, entretanto, o controle químico acaba sendo o preferível, por sua praticidade e flexibilidade. No Brasil, o ingrediente ativo atrazine é utilizado na maioria das áreas de produção de sorgo, direcionado ao controle de plantas daninhas em pré e pós-emergência inicial da cultura, entretanto, o atrazine apresenta espectro de ação limitado a um número relativamente pequeno de gramíneas (RODRIGUES; ALMEIDA, 2015). 
Outro herbicida amplamente utilizado é o 2,4-D, herbicida auxínico, eficiente para o controle de plantas daninhas eudicotiledôneas, seletivo para gramíneas e de baixo custo (SHAW; ARNOLD, 2002).Normalmente esse herbicida é aplicado em pós-emergência, quando as plantas de sorgo apresentam de três a seis folhas e, assim, obtém-se boa seletividade, porque, se for utilizado fora desse período pode haver danos ao desenvolvimento da cultura (TAMADO; MILBERG, 2004; DAN et al., 2010; PETTER et al., 2011).

Para que a produção do sorgo sacarino continue se expandindo no Brasil, é de fundamental importância a identificação de herbicidas, principalmente de ação em pósemergência, com ação sobre gramíneas e latifoliadas, e que apresentem seletividade a essa cultura. Portanto, o objetivo deste trabalho foi avaliar o efeito de diversos herbicidas aplicados em diferentes momentos na cultura do sorgo sacarino.

\section{MATERIAL E MÉTODOS}

$\mathrm{O}$ experimento foi conduzido em casa de vegetação em delineamento inteiramente casualizado com cinco repetições.

A unidade amostral foi representada por vaso de polietileno com capacidade volumétrica de 5 litros, contendo Latossolo Vermelho Escuro, coletado na camada de 0 a $20 \mathrm{~cm}$ de profundidade, cuja análise química realizada pelo Laboratório de química e fertilidade do solo do CCA/UFSCar, apresentava: $\mathrm{P}$ resina $\mathrm{mg} \mathrm{dm}^{-3}=17$; matéria orgânica $=25 \mathrm{~g}$ $\mathrm{dm}^{-3} ; \mathrm{pH}\left(\mathrm{CaCl}_{2}\right)=5,7 ; \mathrm{K}, \mathrm{Ca}, \mathrm{Mg}$ e $\mathrm{H}+\mathrm{Al}\left(\mathrm{mmol}_{\mathrm{c}} / \mathrm{dm}^{3}\right)=2,2$, 46,12 e 15 respectivamente; SB, CTC e V $(\%)=60,2 ; 75,2$ e 80.

Para a semeadura do cultivar de sorgo sacarino BRS511 foram utilizadas cinco sementes por vaso, na profundidade de $2 \mathrm{~cm}$. Os vasos foram submetidos à irrigação durante todo $o$ período experimental, a fim de se manter a umidade do solo para o pleno desenvolvimento das plantas $(8 \mathrm{~mm}$ de água por dia, divididos em dois ciclos). Os vasos foram separados para dois experimentos: um com utilização de herbicidas em préemergência da cultura e outro para utilização de herbicidas em pós-emergência da cultura.

Os herbicidas aplicados em pré-emergência (um dia após a semeadura do sorgo) e suas doses foram: atrazine (1250, 1875, 2500, $3125 \mathrm{~g}$ i.a ha $\left.{ }^{-1}\right)$, atrazine+simazine (2000, 3000, 4000, $5000 \mathrm{~g}$ i.a ha $\left.{ }^{-1}\right)$, hexazinone $(187,5,281,25,375,468,75 \mathrm{~g}$ i.a $\left.\mathrm{ha}^{-1}\right)$ e s-metolachlor $\left(840,1260,1680,2100 \mathrm{~g}\right.$ i.a ha $\left.{ }^{-1}\right)$ o que corresponde respectivamente a $0,50 \mathrm{D} ; 0,75 \mathrm{D} ; 1,0 \mathrm{D}$ e $1,25 \mathrm{D}$, sendo $\mathrm{D}$ a dose comercial, em pré-emergência da cultura, além de testemunha sem aplicação de herbicida.

Os herbicidas aplicados em pós-emergência, quando as plantas de sorgo apresentavam três folhas, e suas diferentes doses foram: haloxyfop-methyl $\left(30,45,60,75 \mathrm{~g}\right.$ i.a ha $\left.{ }^{-1}\right)$, cyhalofop-butil $\left(100,150200,250 \mathrm{~g}\right.$ i.a ha $\left.{ }^{-1}\right)$, fomesafem $(125$, $187,5,250,312,5 \mathrm{~g}$ i.a ha $\left.{ }^{-1}\right)$, imazaquim $(80,120,160,200 \mathrm{~g}$ i.a ha $\left.{ }^{-1}\right)$, lactofen $\left(90,135,180,225 \mathrm{~g}\right.$ i.a ha $\left.{ }^{-1}\right)$, atrazine $(1250$, $1875,2500,3125$ g i.a ha-1), 2,4-D (250, 375, 500, 625 g i.a ha $\left.^{-1}\right)$ e saflufenacil $\left(50,75,100,125 \mathrm{~g}\right.$ i.a ha- $\left.{ }^{1}\right)$, o que corresponde respectivamente a $0,50 \mathrm{D} ; 0,75 \mathrm{D} ; 1,0 \mathrm{D}$ e $1,25 \mathrm{D}$, sendo D a dose comercial de cada herbicida e testemunha sem aplicação dos herbicidas.

Todos os tratamentos foram pulverizados utilizando-se um pulverizador costal, pressurizado a $\mathrm{CO}_{2}$, com pressão de 30 $\mathrm{lb} / \mathrm{pol}^{2}$, equipado com barra com quatro bicos do tipo leque, XR 110.03, espaçados entre si de $0,50 \mathrm{~m}$, com volume de calda de $200 \mathrm{~L} \mathrm{ha}^{-1}$. Por ocasião da aplicação, a umidade relativa do ar, velocidade do vento e temperatura média do ar foram medidas pela estação meteorológica Kestrel em: $65 \%, 2,4 \mathrm{~m} \mathrm{~s}$ ${ }^{1}$ e $24^{\circ} \mathrm{C}$, respectivamente.

Os efeitos dos tratamentos sobre a cultura do sorgo foram avaliados aos 7, 14, 21 e 30 dias após a aplicação dos tratamentos (DAT), de acordo com os sintomas visuais de fitointoxicação, numa escala de $0 \%$ (zero) a $100 \%$, em que 0 (zero) equivale a nenhum dano visível na planta e $100 \%$, à morte da planta. Aos 30 DAA foi determinada a biomassa seca da parte aérea, obtida pela pesagem do material colhido e seco em estufa de circulação forçada $\left(70 \pm 2^{\circ} \mathrm{C}\right)$ por 72 horas até obtenção de peso constante.

Os dados foram submetidos a análise de variância e, quando significativos, as médias qualitativas foram comparadas pelo teste Tukey a 5\% de probabilidade e para as médias quantitativas, ajustadas curvas de regressão.

\section{RESULTADOS}

Para os herbicidas 2,4-D e atrazine não foram constatadas diferenças significativas com relação à testemunha em todas as épocas avaliadas, portanto, os dados de fitointoxicação não foram representados em gráficos (Tabela 1).

Tabela1. Fitointoxicação causada pelas diferentes doses aplicadas em pós-emergência de 2,4-D e atrazine aos 7, 14, 21 e 30 DAT em plantas de Sorghum bicolor.

Table 1. Phytointoxication caused by the different post-emergence doses of 2,4-D and atrazine at 7, 14, 21 and 30 DAT in Sorghum bicolor.

\begin{tabular}{ccccc}
\hline $\begin{array}{c}\text { \% de dose } \\
\text { comercial }\end{array}$ & \multicolumn{5}{c}{$\%$ de Fitointoxicação } \\
\hline $2,4-\mathrm{D}$ & 7 DAT & 14 DAT & 21 DAT & 30 DAT \\
\hline 0D & 0,00 & 0,00 & 0,00 & 0,00 \\
$0,5 \mathrm{D}$ & 12,50 & 15,00 & 10,00 & 10,00 \\
$0,75 \mathrm{D}$ & 15,00 & 12,50 & 12,50 & 12,50 \\
1D & 5,00 & 12,50 & 12,50 & 12,50 \\
1,25D & 17,50 & 20,00 & 20,00 & 20,00 \\
\hline atrazine & 7 DAT & 14 DAT & 21 DAT & 30 DAT \\
\hline 0D & 0,00 & 0,00 & 0,00 & 0,00 \\
$0,5 \mathrm{D}$ & 0,00 & 0,00 & 0,00 & 0,00 \\
$0,75 \mathrm{D}$ & 0,00 & 0,00 & 0,00 & 0,00 \\
1D & 0,00 & 2,50 & 5,00 & 5,00 \\
1,25D & 0,00 & 0,00 & 10,00 & 10,00 \\
\hline
\end{tabular}

Nos tratamentos envolvendo os herbicidas haloxyfop metil e cyhalofop-butil, puderam ser observados valores crescentes de fitointoxicação nas plantas de sorgo, sendo que os sintomas iniciais foram observados no tecido meristemático (Figuras 1A e 1B). Observou-se que o herbicida haloxyfop-metil provocou taxas de fitointoxicação acima de $60 \%$, aos 21 DAT, quando utilizada a dose comercial, enquanto que aos 30 DAT, a dose de $0,75 \mathrm{D}$ já provocou fitointoxicação acima de $60 \%$ (Figura 1A).

Nos tratamentos envolvendo diferentes doses de cyhalofop-butil, nota-se uma curva pouco acentuada para 7 e 14 DAT, com taxas de fitointoxicação de até $30 \%$ para $1,25 \mathrm{D}$. Já aos 21 DAT, os valores observados passaram de 40\% nas doses acima de $0,75 \mathrm{D}$. Aos $30 \mathrm{DAT}$, puderam ser observados valores próximos de $60 \%$ para as doses acima de $0,75 \mathrm{D}$, que já poderiam acarretar em riscos severos para a produção (Figura 1B).

O herbicida indaziflam tem como mecanismo de ação a inibição de biossíntese de celulose, que pode resultar em 
inchaço radial e lignificação. Para esse herbicida, os valores de fitointoxicação nas plantas aos 7 e 14 DAT foram pouco expressivos. Já aos 21 e 30 DAT, houve aumento nos efeitos fitotóxicos, chegando a 50\% nas maiores doses, que já podem ser caracterizados como danos severos à muito severos (Figura 2A).
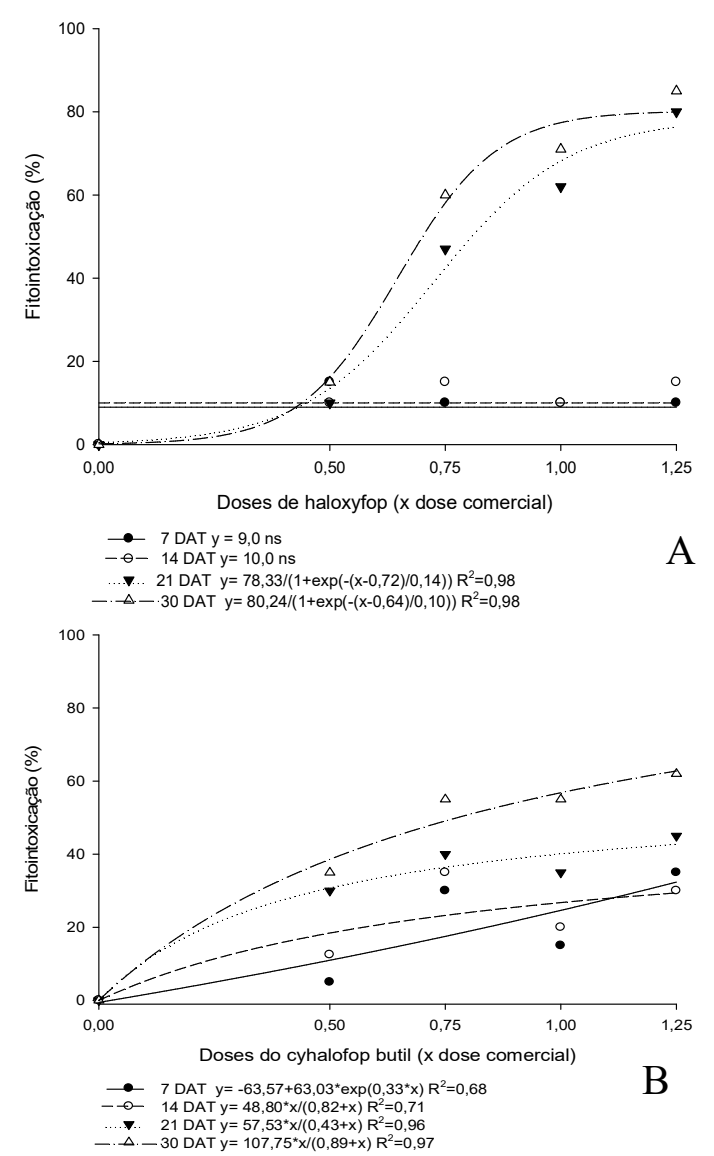

A

(n)

Figura 1. Fitointoxicação causada pelas diferentes doses aplicadas em pós-emergência de haloxyfop e cyhalofopbutil aos 7, 14, 21 e 30 DAT em Sorghum bicolor.

Figure 1. Phytointoxication caused by the different post-emergence doses of haloxyfop and cyhalofop butyl at 7, 14, 21 and 30 DAT in Sorghum bicolor.

Para as dosagens de imazaquim, é possível perceber um incremento gradual na fitointoxicação de acordo com os períodos de avaliação, comportamento típico de produtos que têm como mecanismo de ação a inibição da enzima acetolactatosintase - ALS. Na última avaliação realizada, as maiores doses (1D e 1,25D) provocaram fitointoxicação próxima a $80 \%$ (Figura $2 \mathrm{~B}$ ).

Os herbicidas saflufenacil, lactofen e fomesafen, inibidores da enzima protoporfirinogênio oxidase (PROTOX) apresentaram curvas similares quanto a fitointoxicação em função das diferentes doses utilizadas (Figura 3). O uso de saflufenacil não provocou diferença estatística aos 7 e 14 DAT, com média de fitointoxicação nas plantas de sorgo de 10 e $12 \%$, respectivamente. Já aos 21 e 30 DAT observou-se aumento na fitointoxicação a partir da dose $1 \mathrm{D}$, chegando à $70 \%$ aos 30 DAT na dose de 1,25D (Figura 3A). Para lactofen, aos 7 e 14 DAT não foram observadas diferenças significativas entre as doses utilizadas, com valores médios de fitointoxicação de 14 e 10\%, respectivamente. Aos 21 e 30 DAT observou-se leve aumento da fitointoxicação na maior dose, mas ainda assim abaixo de 25\% (Figura 3B).

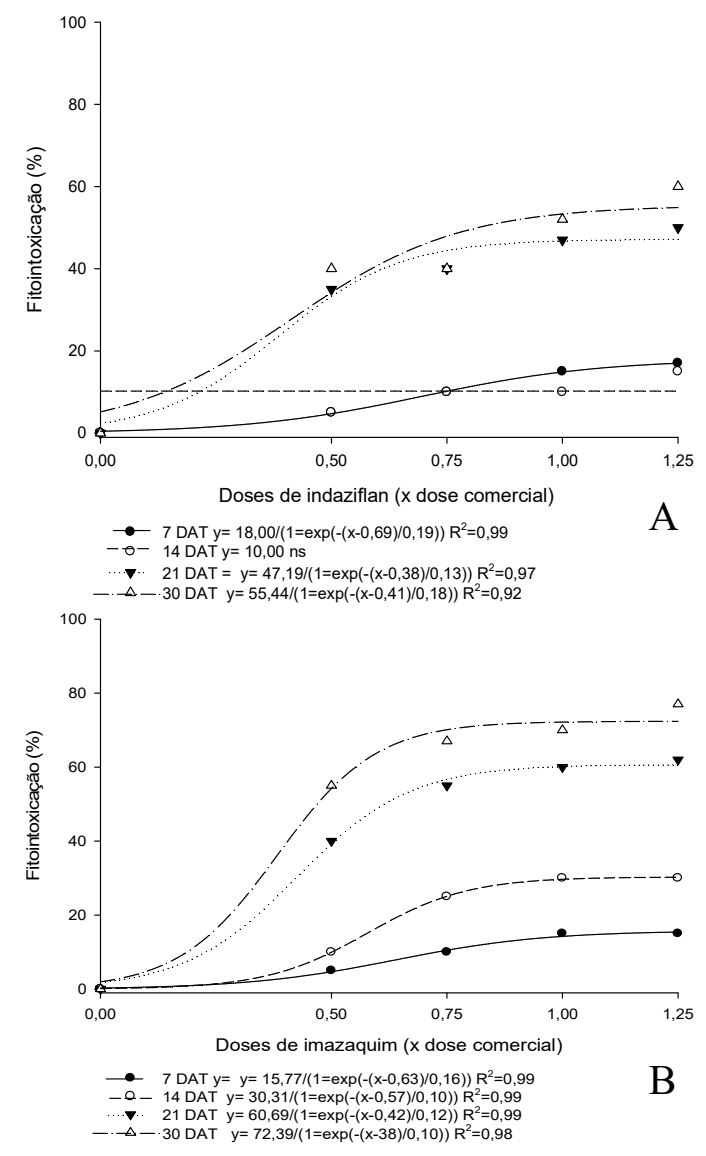

Figura 2. Fitointoxicação causada pelas diferentes doses aplicadas em pós-emergência de indaziflam e imazaquim aos 7, 14, 21 e 30 DAT em Sorghum bicolor.

Figure 2. Phytointoxication caused by the different post-emergence doses of indaziflam and imazaquim at 7, 14, 21 and 30 DAT in Sorghum bicolor.

Já para fomesafem, em todas as datas de avaliação a curva se manteve similar, apresentando valores crescentes de fitointoxicação em função da dose utilizada, alcançando $45 \%$ para a dose de 1,25 D aos 30 DAT (Figura 4).

Com relação à biomassa seca da parte aérea, foram observadas diferenças significativas nos tratamentos envolvendo 2,4-D, cyhalofop-butil, imazaquim, indaziflan, haloxyfop-metil e saflufenacil com menor acúmulo de biomassa, com o aumento da dose dos herbicidas, e não foram detectadas diferenças significativas nos tratamentos com fomesafen e lactofen (Tabela 2).

As porcentagens de fitointoxicação causadas pelos herbicidas aplicados em pré-emergência em Sorghum bicolor da variedade BRS511 podem ser observadas nas Figuras 5 e 6. Nos tratamentos com atrazine e a mistura atrazine+simazine, observou-se fitointoxicação acima de $20 \%$ após os 21 DAT apenas a partir do tratamento 1D (Figura 5 A e B).

O herbicida hexazinone provocou fitointoxicação elevada após os 21 DAT, com valores superiores a $60 \%$ para as doses acima de $0,75 \mathrm{D}$, e chegando a $100 \%$ de fitointoxicação aos 30 DAT em todas as doses (Figura $6 \mathrm{~A}$ ). A utilização de smetolachlor também ocasionou elevados índices de fitointoxicação, sendo que aos 14 DAT observaram-se valores acima de $50 \%$ de fitointoxicação e aos 21 e 30 DAT fitointoxicação de $100 \%$ a partir do tratamento $0,75 \mathrm{D}$ (Figura 6 B). Com relação à produção de biomassa, todos os tratamentos e doses apresentaram diferenças significativas 
(Tabela 5), destacando-se de maneira negativa hexazinone e smetolachlor.
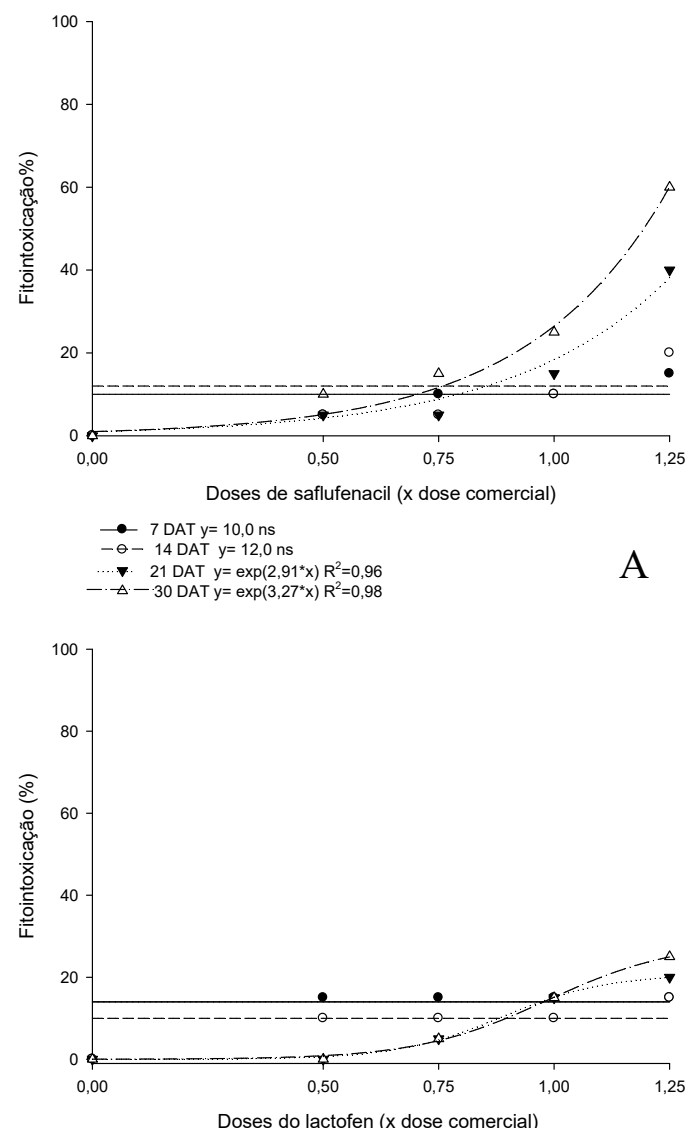

Tabela 2. Biomassa seca da parte aérea (g) de Sorghum bicolor tratados com os herbicidas 2,4-D, cyhalofop-butil (CYH), fomesafem (FOM), imazaquim (IMZ), indaziflam (IND), lactofen (LAC), haloxyfop (HALO), atrazine (ATR) e saflufenacil (SAFL) em diferentes doses aplicadas em pós-emergência.

Table 2. Dry biomass of Sorghum bicolor aerial part treated with the herbicides 2,4-D, cyhalofop-butyl (CYH), fomesafem (FOM), imazaquim (IMZ), indaziflam (IND), lactofen (LAC), haloxyfop (HALO), atrazine (ATR), and saflufenacil (SAFL) at different postemergence doses.

\begin{tabular}{cccccc}
\hline \% de dose & \multicolumn{5}{c}{ Biomassa seca $(\mathrm{g})$} \\
\cline { 2 - 6 } & $2,4-\mathrm{D}$ & CYH & FOM & IMZ \\
\hline 0 & $0,41 \mathrm{a}$ & $0,41 \mathrm{a}$ & $0,41 \mathrm{a}$ & $0,41 \mathrm{a}$ \\
0,5 & $0,27 \mathrm{ab}$ & $0,35 \mathrm{ab}$ & $0,39 \mathrm{a}$ & $0,20 \mathrm{a}$ \\
0,75 & $0,35 \mathrm{ab}$ & $0,31 \mathrm{ab}$ & $0,36 \mathrm{a}$ & $0,26 \mathrm{a}$ \\
1 & $0,26 \mathrm{ab}$ & $0,23 \mathrm{~b}$ & $0,34 \mathrm{a}$ & $0,26 \mathrm{a}$ \\
1,25 & $0,21 \mathrm{~b}$ & $0,23 \mathrm{~b}$ & $0,32 \mathrm{a}$ & $0,23 \mathrm{~b}$ \\
\hline CV $(\%)$ & 27,91 & 25,24 & 23,59 & 39,3 \\
\hline$\%$ de dose & \multicolumn{6}{c}{ Biomassa seca $(\mathrm{g})$} \\
\hline \multicolumn{7}{c}{ LAC } & HALO & ATR \\
\hline $0 \mathrm{D}$ & $0,41 \mathrm{a}$ & $0,41 \mathrm{a}$ & $0,41 \mathrm{a}$ & $0,41 \mathrm{a}$ & $0,41 \mathrm{a}$ \\
$0,5 \mathrm{D}$ & $0,38 \mathrm{ab}$ & $0,26 \mathrm{a}$ & $0,15 \mathrm{ab}$ & $0,17 \mathrm{~b}$ & $0,22 \mathrm{~b}$ \\
$0,75 \mathrm{D}$ & $0,31 \mathrm{abc}$ & $0,40 \mathrm{a}$ & $0,22 \mathrm{ab}$ & $0,17 \mathrm{~b}$ & $0,22 \mathrm{~b}$ \\
$1 \mathrm{D}$ & $0,21 \mathrm{c}$ & $0,28 \mathrm{a}$ & $0,17 \mathrm{ab}$ & $0,10 \mathrm{~b}$ & $0,25 \mathrm{~b}$ \\
$1,25 \mathrm{D}$ & $0,28 \mathrm{bc}$ & $0,28 \mathrm{a}$ & $0,12 \mathrm{~b}$ & $0,21 \mathrm{~b}$ & $0,19 \mathrm{~b}$ \\
\hline CV $(\%)$ & 18,69 & 41,02 & 58,48 & 42,94 & 24,86 \\
\hline
\end{tabular}

Letras minúsculas iguais entre colunas não diferem estatisticamente a $5 \%$ de significância.

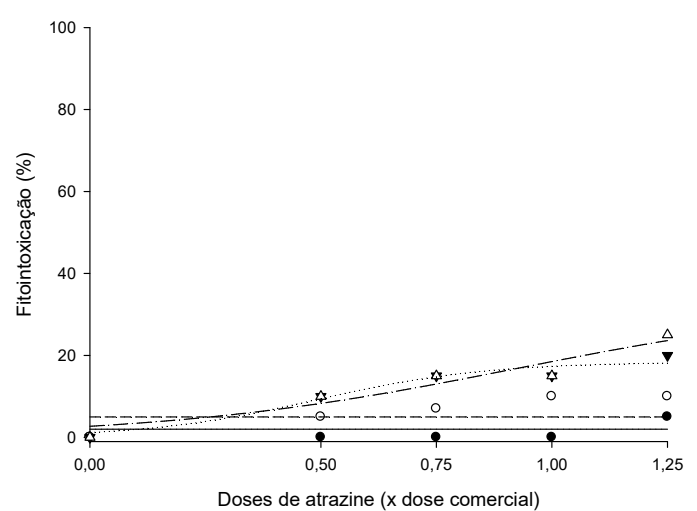

$\longrightarrow$
$\longrightarrow-14$ DAT $y=2,0 \mathrm{~ns}$
$-\rightarrow-21$ DAT $y=5,0 \mathrm{~ns}$

- 21 DAT $y=18,42 /(1=\exp (-(x-0,49) / 0,18)) R^{2}=0,95$ -. $\triangle-30$ DAT $y=33,64 /(1=\exp (-(x-0,92) / 0,38)) R^{2}=0,91$

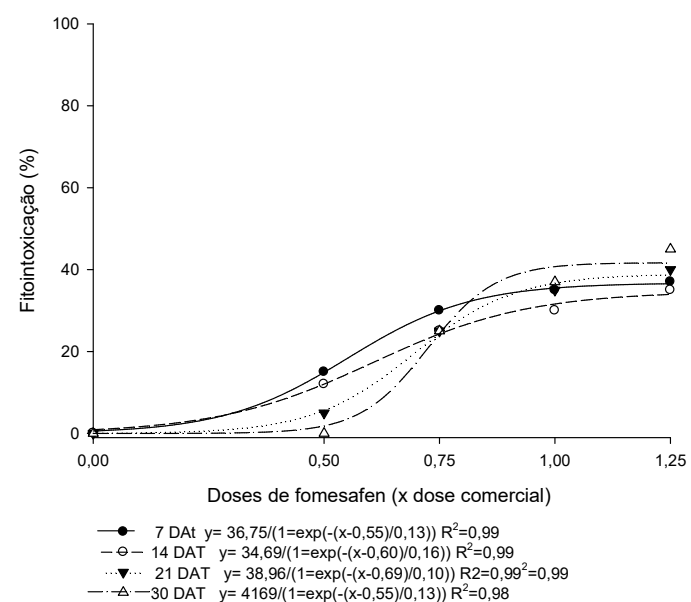

Figura 4. Fitointoxicação causada pelas diferentes doses aplicadas em pós-emergência de fomesafen aos 7, 14, 21 e 30 DAT em Sorghum bicolor.

Figure 4. Phytointoxication caused by the different post-emergence doses of fomesafen at 7, 14, 21 and 30 DAT in Sorghum bicolor.

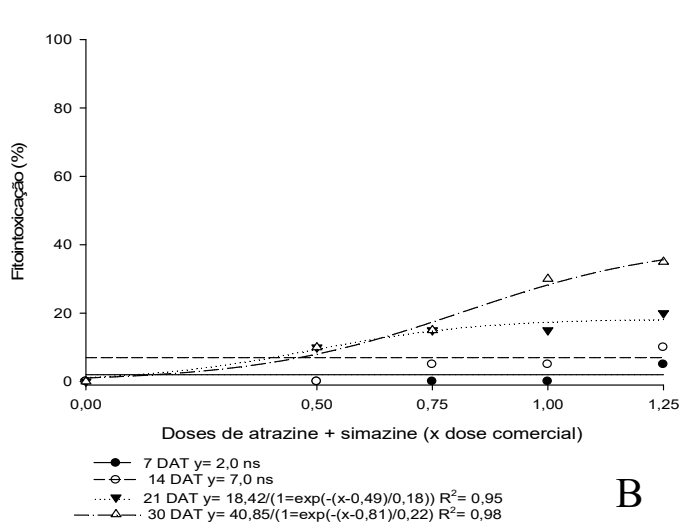

Figura 5. Fitointoxicação causada pelas diferentes doses aplicadas em pré-emergência de atrazine e atrazine + simazine aos 7, 14, 21 e 30 DAT em Sorghum bicolor.

Figure 5. Phytointoxication caused by the different pre-emergency doses of atrazine and atrazine + simazine at 7, 14, 21 and 30 DAT in Sorghum bicolor. 

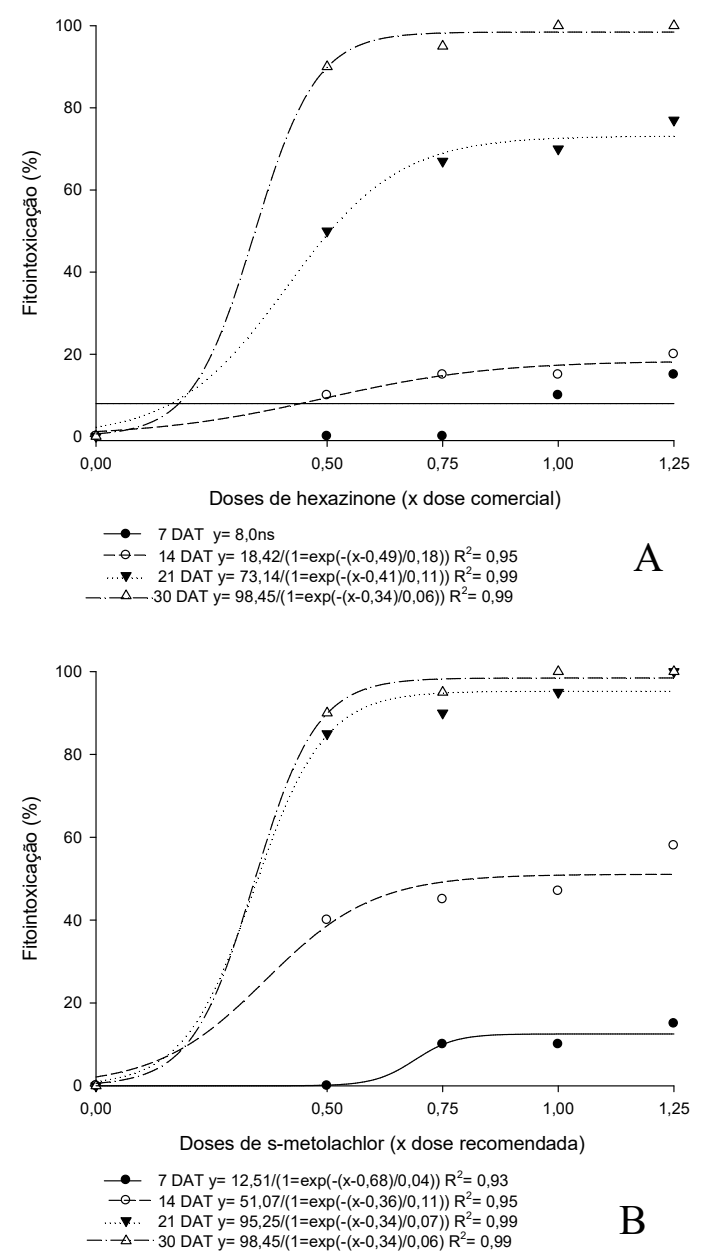

Figura 6. Fitointoxicação causada pelas diferentes doses aplicadas em pré-emergência de hexazinone e s-metolachlor aos 7, 14, 21 e 30 DAT em Sorghum bicolor.

Figure 6. Phytointoxication caused by the different pre-emergency doses of hexazinone and s-metolachlor at 7, 14, 21 and 30 DAT in Sorghum bicolor.

Tabela 5. Biomassa seca da parte aérea ( $\mathrm{g}$ ) de Sorghum bicolor para os herbicidas atrazine, atrazine+simazine, hexazinone e smetolachlor em diferentes doses aplicadas em pré-emergência.

Table 5. Dry biomass of aerial part $(\mathrm{g})$ of Sorghum bicolor for the herbicides atrazine, atrazine + simazine, hexazinone and $\mathrm{s}$ metolachlor in different doses applied in pre-emergence.

\begin{tabular}{|c|c|c|c|c|}
\hline \multirow[t]{2}{*}{$\begin{array}{l}\% \text { de dose } \\
\text { comercial }\end{array}$} & \multicolumn{4}{|c|}{ Biomassa seca (g) } \\
\hline & ATR & ATR + SIM & HEX & S-MET \\
\hline $0 \mathrm{D}$ & $0,19 a b$ & $0,19 \mathrm{ab}$ & $0,19 \mathrm{a}$ & $0,19 \mathrm{a}$ \\
\hline $0,5 \mathrm{D}$ & $0,19 \mathrm{ab}$ & $0,13 \mathrm{ab}$ & $0,00 \mathrm{~b}$ & $0,00 \mathrm{~b}$ \\
\hline $0,75 \mathrm{D}$ & $0,22 \mathrm{a}$ & $0,08 \mathrm{~b}$ & $0,00 \mathrm{~b}$ & $0,00 \mathrm{~b}$ \\
\hline $1 \mathrm{D}$ & $0,13 \mathrm{~b}$ & $0,14 a b$ & $0,00 \mathrm{~b}$ & $0,00 \mathrm{~b}$ \\
\hline $1,25 \mathrm{D}$ & $0,16 \mathrm{ab}$ & $0,14 \mathrm{ab}$ & $0,00 \mathrm{~b}$ & $0,00 \mathrm{~b}$ \\
\hline CV (\%) & 17,69 & 37,39 & 20,37 & 20,37 \\
\hline
\end{tabular}

Letras minúsculas iguais entre colunas não diferem entre si pelo teste de Tukey $5 \%$.

\section{DISCUSSÃO}

A baixa fitointoxicação provocada por 2,4-D e atrazine possibilita o uso em pós-emergência na cultura do sorgo sacarino, entretanto, vale ressaltar que o uso do 2,4-D está relacionado à dose e época de aplicação. Petteret al. (2011), por exemplo, verificaram que o efeito fitotóxico do 2,4-D prejudicou a produtividade do sorgo em doses acima de 1.005 $\mathrm{g} \mathrm{ha}^{1}$ realizada em aplicações tardias. No caso do uso da atrazine, Archangelo et al. (2002) avaliaram que a aplicação precoce de atrazine foi prejudicial à cultura do sorgo forrageiro, diferentemente, do que ocorreu quando as aplicações foram mais tardias. No entanto, independente da dose utilizada e do estádio da cultura no momento da aplicação, as plantas apresentaram tendência de recuperação do desenvolvimento ao longo do tempo. Isso explica porque o uso do herbicida atrazine em sorgo tem sido recomendado por diversos autores (MITCHELL et al., 2011; FROMME et al., 2012), por apresentar fitointoxicação nula ou muito baixa.

Com relação à alta fitointoxicação observada com o uso de haloxyfop metil e cyhalofop-butil, vale lembrar que estes herbicidas têm como mecanismo de ação a inibição da enzima acetilCoAcarboxilase (ACCase), uma das responsáveis pela síntese de ácidos graxos, que constituem lipídios de membranas de células e organelas, reguladores de permeabilidade seletiva (BURKE et al. 2006). A inibição da ACCaseuniprotéica ocorre em espécies da família Poaceae, por este motivo, muitas vezes os herbicidas desse mecanismo de ação também são chamados de graminicidas.

O indaziflam também provocou alta fitointoxicação e está sendo posicionado para o controle de gramíneas anuais, as doses oscilam de 25 a $100 \mathrm{~g} \mathrm{ha}^{-1}$, podendo atingir $150 \mathrm{~g} \mathrm{ha}^{-1}$ em espécies mais tolerantes (MYERS et al., 2009; KAAPRO; HALL, 2012). Outra característica importante do indaziflam é seu elevado período residual no solo, sendo superior a 150 dias, persistindo no solo por mais tempo em relação a outros herbicidas de aplicação em pré-emergência, o que permite por um lado maior flexibilidade quanto à época de aplicação, por outro, pode provocar carryover em culturas sucedâneas sensíveis como o próprio sorgo sacarino (KAAPRO; HALL 2012).

Já a grande sensibilidade do sorgo ao imazaquim justifica o uso dessa planta como bioindicador em trabalhos envolvendo lixiviação e carryover (INOUE et al., 2002).

Com relação à resposta das plantas de sorgo aos inibidores da PROTOX, Correia e Gomes (2015) estudaram a seletividade do herbicida saflufenacil para dois híbridos de sorgo sacarino, quando pulverizado em pré e pós-emergência, além do uso de Na-bentazon como safener para saflufenacil e observaram que o híbrido CVSW 80147 foi mais tolerante ao saflufenacil do que o CVSW 80007, em aplicações em pré ou pós-emergência e que o Na-bentazon mostrou-se promissor para uso como safener nas aplicações em pós-emergência de saflufenacil em sorgo sacarino para dosagens de até $70 \mathrm{~g}$ i.a. $\mathrm{ha}^{-1}$.

Santos (1991) constatou que o fomesafen causou redução no crescimento da parte aérea de plantas de sorgo até 100 dias após sua aplicação em todas as doses testadas $(125,250$ e 375 g i.a. ha ${ }^{-1}$ )

Os dados de fitointoxicação em sorgo com o uso de atrazine em pré-emergência, se assemelhou ao trabalho de Concenço et al. (2012) que constataram que o herbicida atrazine, aplicado em pré-emergência das plantas daninhas na cultura do sorgo-sacarino, controlou mais de $92 \%$ da infestação, com doses entre 1.500 e 3.000 g i.a. ha ${ }^{-1}$ sem causar grande fitotoxicidade na cultura.

O efeito fitotóxico do s-metolachlor também já foi observado por outros pesquisadores. Galon et al. (2016) e Silva et al. (2016) verificaram que as cultivares de sorgo 
sacarino foram sensíveis a atrazine $+\mathrm{s}$-metolachlor e a smetolachlor aplicados em pré-emergência.

A intoxicação do sorgo ocasionada por esse herbicida está relacionada à incapacidade das plantas de degradarem o smetolachlor em compostos não tóxicos para a cultura. Nos EUA o herbicida s-metolachlor está registrado para a cultura do sorgo, entretanto, o seu uso está atrelado a utilização de safeners que estimulam a detoxificação do herbicida pelas plantas (ARCHANGELO et al. 2012). O uso de cloroacetanilidas (alachlor, metolachlor e acetochlor) representa quase sempre reduções severas do "stand" da cultura (SILVA et al., 1986).

\section{CONCLUSÕES}

Conclui-se que os herbicidas atrazine, 2,4-D e lactofen podem ser utilizados em aplicações em pós-emergência na cultura do sorgo sacarino, enquanto os herbicidas atrazine e atrazine + simazine podem ser utilizados para aplicações em pré-emergência sem afetar o desenvolvimento inicial das plantas de sorgo sacarino.

\section{REFERÊNCIAS}

ARCHANGELO, E. R.; SILVA, A. A.; SILVA, J. B.; KARAM, D. Seletividade e eficácia de herbicidas aplicados em pós-emergência na cultura do sorgo forrageiro. Revista Brasileira de Milho e Sorgo, Sete Lagoas, v.1, n.3, p.107-115, 2002. DOI: http://dx.doi.org/10.18512/1980-

6477/rbms.v1n03p\%25p

BURKE, I. C.; THOMAS, W. E.; BURTON, J. D.; SPEARS J. F.; WILCUT J. W. A seedling assay to screen aryloxyphenoxypropionic acid and cyclohexanedione resistance in johnsongrass (Sorghum halepense). Weed Technology, Faytteville, v. 20, n. 4, p. 950-955, 2006. DOI: https://dx.doi.org/10.1614/WT-05-160.1

CONCENÇO, G.; ANDRES, A.; CECCON, G. Manejo de plantas daninhas na cultura do sorgo sacarino. 1. ed. Embrapa Agropecuária Oeste, 2012. 5 p. (Comunicado Técnico, 2004)

CORREIA, N. M.; GOMES, L. J. P. Selectivity of saflufenacil for sweet sorghum and potential use of Na-Bentazon as a Safener. Planta Daninha. Viçosa, v. 33, p. 267-274, 2015. DOI: 83582015000200012

DAN, H. A.; DAN, L. G. M.; BARROSO, A. L. L.; OLIVEIRA JR. R. S.; GUERRA, N.; FELDKIRCHER, C. Tolerância do sorgo granífero ao 2,4-D aplicado em pósemergência. Planta Daninha, Viçosa, v. 28, p. 785-792, 2010. DOI: http://dx.doi.org/10.1590/S010083582010000400011

FROMME, D. D.; DOTRAY, P. A.; GRICHAR, W. J.; FERNANDEZ, C. J. Weed control and grain sorghum (Sorghum bicolor) tolerance to pyrasulfotole plus bromoxynil. International Journal of Agronomy, Davis, v. 2012, p. $1-10, \quad 2012$. DOI: http://dx.doi.org/10.1155/2012/951454

GALON, L.; FERNANDES, F. F.; ANDRES, A.; SILVA, A. F.; FORTE, C. T. Selectivity and efficiency of herbicides in weed control on sweet sorghum. Pesquisa Agropecuária Tropical, v. 46, n. 2, p. 123-131, 2016 DOI: http://dx.doi.org/10.1590/1983-40632016v4639431

GIACOMINI, I.; PEDROZA, M. M.; SIQUEIRA, F. L. T.; MELLO, S. Q. S.; CERQUEIRA, F. B.; SALLA, L. Uso potencial de sorgo sacarino para a produção de etanol no estado do Tocantins. Revista Agrogeoambiental, Pouso

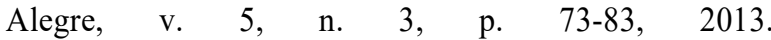
http://dx.doi.org/10.18406/2316-1817v5n32013531

INOUE, M. H.; MARCHIORI JR., O.; OLIVEIRA JR., R. S.; CONSTANTIN, J.; TORMENA, C. A. Calagem e o potencial de lixiviação de imazaquin em colunas de solo. Planta Daninha, v. 20, n. 1, p. 125-132, 2002. DOI: http://dx.doi.org/10.1590/S0100-83582002000100016

KAAPRO, J.; HALL, J. Indaziflam, a new herbicide for preemergent control of weeds in turf, forestry, industrial vegetation and ornamentals. Pakistan Journal of Weed Science Research, Peshawar, v. 18, p. 267-270, 2012.

MITCHELL, G. D. W.; BARTLETT, D. W.; FRASER, T. E, HAWKES, T. R.; HOLT, D. C; TOWNSON, J. K.; WICHERT, R. A. Mesotrione: A new selective herbicide for use in maize. Pest Management Science, v. 57, p. 120 128, 2011. DOI: https://dx.doi.org/10.1002/15264998(200102)57:2\%3C120::AID-PS254\%3E3.0.CO;2-E

MYERS, D. F.; HANRAHAN, R.; MICHEL, J.; MONKE, B.; MUDGE, L. Indaziflam/BCS AA170717 a new herbicide for preemergent control of grasses and broadleaves in turf and ornamentals. Proceedings - Southern Weed Science Society, Westminster, v. 62, p. 393, 2009.

PETTER, F. A.; PACHECO, L. P.; ALCÂNTARA NETO, F.; ZUFFO, A. M.; PROCÓPIO, S. O.; ALMEIDA, F. A. Desempenho agronômico do sorgo em função de doses e épocas de aplicação do herbicida 2,4-D. Planta Daninha, Viçosa, v. 29, n. esp., p. 1091-1098, 2011. DOI: http://dx.doi.org/10.1590/S0100-83582011000500016

RODRIGUES, A. C. P.; COSTA, N. V.; CARDOSO, L. A.; CAMPOS, C. F.; MARTINS, D. Períodos de interferência de plantas daninhas na cultura do sorgo. Planta Daninha, Viçosa, v. 28, n. 1, p. 23-31, 2010. DOI: http://dx.doi.org/10.1590/S0100-83582010000100003

RODRIGUES, B. N.; ALMEIDA, F. S. Guia de herbicidas. 6. ed. Londrina: IAPAR, 2015.697 p.

ROSALES-ROBLES, E.; SANCHEZ-DE-LA-CRUZ, R.; RODRIGUEZ-DEL-BOSQUE, L. A. Tolerância de sorgo para grano a los herbicidas. Revista fitotecnia mexicana, Chapingo, v. 37, p. 89-94, mar. 2014.

SANTOS, J. G. M. Controle químico de plantas daninhas na cultura do feijão (Phaseolus vulgaris L.), no inverno. 1991. 86f. Dissertação (Mestrado em Fitotecnia) Universidade Federal de Viçosa, 1991.

SILVA, J. B. da; PASSINI, T.; VIANA, A. C. Controle de plantas daninhas na cultura do sorgo. Informe Agropecuário, v. 12, n. 144, p. 43-45, 1986.

SHAW, D. R.; ARNOLD, J. C. Weed control from herbicide combinations with glyphosate. Weed Technology, Faytteville, v. 16, n. 1, p. 1-6, 2002. DOI: https://dx.doi.org/10.1614/0890037X(2002)016[0001:WCFHCW]2.0.CO;2

TAMADO, T.; MILBERG, P. Control of Parthenium (Parthenium hysterophorus) in Grain Sorghum (Sorghum bicolor) in the Smallholder Farming System in Eastern Ethiopia1. Weed Technology, v. 18, p.100-105, jan. 2004. DOI: http://dx.doi.org/10.1614/WT-03-033R

TAMADO, T.; SCHUTZ, W.; MILBERG, P. Germination ecology of the weed Parthenium hysterophorus in eastern Ethiopia. Annals Applied Biology, Newport, v. 140, n. 2, p. 263-270, 2002. DOI: https://dx.doi.org/10.1111/j.17447348.2002.tb00180.x 